Article

\title{
Experimental Investigation of the Mechanical and Durability Properties of Crumb Rubber Concrete
}

\author{
Hanbing Liu ${ }^{1}$, Xianqiang Wang ${ }^{1}$, Yubo Jiao ${ }^{1, *}$ and Tao Sha ${ }^{1,2}$ \\ 1 College of Transportation, Jilin University, Changchun 130025, China; lhb@jlu.edu.cn (H.L.); \\ wangxq14@mails.jlu.edu.cn (X.W.); taoj114@mails.jlu.edu.cn (T.S.) \\ 2 Emergency Response Center, Highway Administration of Liaoning Province, Shenyang 110000, China \\ * Correspondence: jiaoyb@jlu.edu.cn; Tel.: +86-136-1079-0678
}

Academic Editor: Jorge de Brito

Received: 2 February 2016; Accepted: 2 March 2016; Published: 7 March 2016

\begin{abstract}
Recycling waste tire rubber by incorporating it into concrete has become the preferred solution to dispose of waste tires. In this study, the effect of the volume content of crumb rubber and pretreatment methods on the performances of concrete was evaluated. Firstly, the fine aggregate and mixture were partly replaced by crumb rubber to produce crumb rubber concrete. Secondly, the mechanical and durability properties of crumb rubber concrete with different replacement forms and volume contents had been investigated. Finally, the crumb rubber after pretreatment by six modifiers was introduced into the concrete mixture. Corresponding tests were conducted to verify the effectiveness of pretreatment methods as compared to the concrete containing untreated crumb rubber. It was observed that the mechanical strength of crumb rubber concrete was reduced, while durability was improved with the increasing of crumb rubber content. $20 \%$ replacement of fine aggregate and $5 \%$ replacement of the total mixture exhibited acceptable properties for practical applications. In addition, the results indicated that the modifiers had a positive impact on the mechanical and durability properties of crumb rubber concrete. It avoided the disadvantage of crumb rubber concrete having lower strength and provides a reference for the production of modified crumb rubber concrete.
\end{abstract}

Keywords: crumb rubber; rubberized concrete; mechanical properties; durability; modifiers

\section{Introduction}

The number of waste tires is continually increasing, as a result of the growing use of transport vehicles [1]. Almost 1000 million waste tires are generated in the world annually. By the year 2030, this number is expected to reach 1200 million [2]. Disposal of waste tires has become a global problem [3]. In many countries, burying the waste tires is a common disposal method, which shortens the service life of the burial ground and causes a very serious threat to ecology. Therefore, effectively reusing waste tires is an urgent and important issue for saving energy and protecting the environment $[4,5]$.

Several methods of recycling waste tires have been proposed, including use as a fuel in cement kilns and to produce carbon black $[3,6]$. These are technically feasible, while bringing great economic waste and environmental pollution. Using recycled rubber as additives to or replacements of construction materials is a highly preferable option. The initial trial of crumb rubber was used as a modifier of asphalt [7]. However, the high viscosity and the higher temperature required in production made it unpractical to be widely used [8]. In order to reuse waste tire rubber effectively, one of the possible solutions is to incorporate it into cement-based material. Partial replacement of mineral aggregates in concrete with waste tire rubber could control environmental pollution and save sandstone resources $[9,10]$. 
Concerning the reuse of waste rubber in concrete, extensive studies had been conducted [11-13]. Two major opposite effects existed when the rubber was introduced into the concrete mixture. The mechanical strength was reduced, while the durability, toughness, impact resistance, strain capacity and sound insulation properties were enhanced [14-17]. Due to the compressive and flexural strengths being two major design criteria in concrete structures, the reduction in the strength of rubberized concrete limited its application $[18,19]$. However, the desirable characteristics, including lower density, higher ductility, better sound insulation and resistance against cracking, made it a valid option for non-structural concrete with a low strength requirement [20-22].

The properties of crumb rubber concrete were significantly affected by rubber content. Ghaly and Cahill [11] studied the compressive strength of concrete with different replacement ratios of crumb rubber by volume (5\%,10\% and $15 \%)$. Compressive strength decreased with the addition of crumb rubber. Yung [5] investigated the durability properties of self-compacting concrete containing waste tire rubber, which indicated that the anti-sulfate corrosion was improved with the increasing of rubber content from $5 \%$ to $20 \%$ of the volume ratio. Holme [17] conducted acoustic tests for concrete with different levels of fine aggregate replacement by crumb rubber $(7.5 \%$ and $15 \%)$. Testing results found that the sound absorbance property of rubberized concrete performed well with higher proportions of rubber. Therefore, the investigation of the advantages and disadvantages of replacing mineral aggregate by crumb rubber is necessary. Additionally, the selected optimal content of crumb rubber in the concrete mixture will bring excellent performance to crumb rubber concrete.

In order to minimize the loss in strength caused by introducing crumb rubber into concrete, prior surface treatment of rubber particles by modifiers was utilized [23]. Mohammadi [14] introduced rubber particles after a water-soaking treatment into the mixture, which significantly enhanced the mechanical strength of crumb rubber concrete. Raghavan et al. [24] pretreated the rubber particles in $\mathrm{NaOH}$ aqueous solution and obtained a high strength performance. Segre and Joekes [25] adopted acid etching, plasma and coupling agents as modifiers to pretreat the crumb rubber. Oiknomou [26] mentioned that the use of SBR latex could minimize the loss in strength compared to the untreated rubber concrete. These pretreatments for crumb rubber enhanced the adherence between the rubber and cement paste, reduced the air content and achieved a uniform distribution of rubber particles in the mixture. However, the comparative analysis and optimization selection of modifiers for the pretreatment of crumb rubber were limited in existing investigations.

This paper investigates the mechanical and durability properties of concrete containing waste crumb rubber. The rubberized concrete was produced by replacing the fine aggregate and mixture with crumb rubber at different volume ratios. Compressive strength, splitting tensile strength, axial compressive strength, the modulus of elasticity, freezing-thawing resistance and sulfate resistance were evaluated for concretes with different contents of crumb rubber. In addition, the crumb rubber was pretreated in six modifiers. Additionally, the effects of modifiers on the properties of crumb rubber concrete were comparatively analyzed and discussed.

\section{Experimental Study}

\subsection{Materials}

Composite Portland cement of Grade 32.5 (normal type) with a specific gravity of 3.12, conforming to GB 175-2007 [27], was used as the cementitious material. The initial setting time was $180 \mathrm{~min}$, and the final setting time was $260 \mathrm{~min}$. The compressive strength of cement mortar was $35.9 \mathrm{MPa}$, which satisfied the design strength requirement. Natural river sand (medium sand) with a fineness modulus of 3.0 was adopted as the fine aggregate. Additionally, the particle size distribution is illustrated in Figure 1. Crushed gravels with a nominal maximum size of $31.5 \mathrm{~mm}$ were used as coarse aggregates. The specific gravity of fine aggregate and coarse aggregate was 2.65 and 2.7, respectively. The water was potable-grade water in the laboratory. 


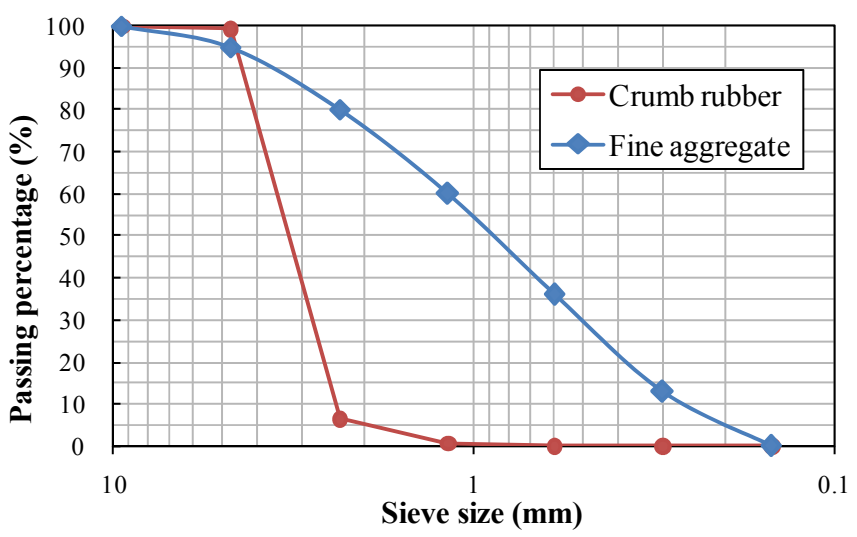

Figure 1. Particle size distribution of fine aggregate and crumb rubber.

Crumb rubber with the particle size $(2-4 \mathrm{~mm})$ specially used to pave a rubber runway was selected as the replacement material, as shown in Figure 2. The specific gravity was 1.2, and the particle size distribution is also shown in Figure 1. Corresponding studies indicated that the concrete containing 2-4 mm crumb rubber had superior properties [28]. The geometric configuration of crumb rubber was an uneven prism, which could enhance the bonding between rubber particles and cement paste. Hardness and elasticity were also better than general rubber.

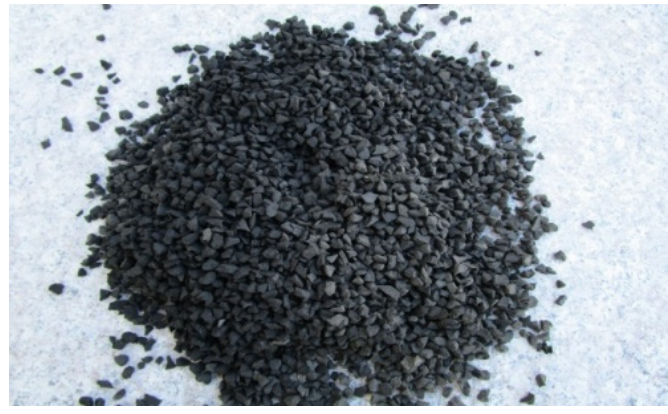

(a)

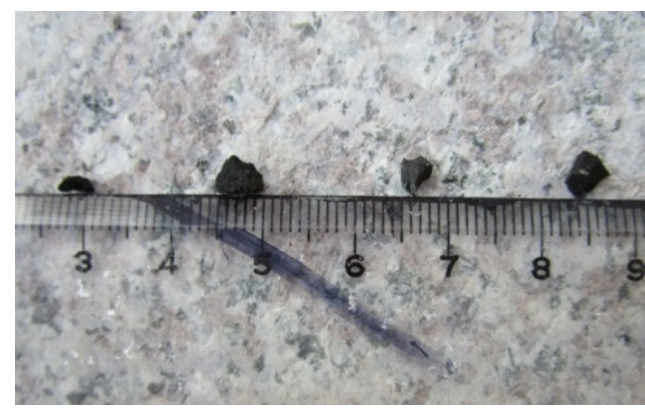

(b)

Figure 2. Crumb rubber with a size of $2-4 \mathrm{~mm}$. (a) Crumb rubber; (b) particle size.

Modifiers for the pretreatment of crumb rubber, including emulsion, ethoxyline resin, synthetic resin, amino-acrylate (contact glue), chloroprene adhesive and unsaturated resins (marble glue), were commonly used in decoration and construction engineering. They had satisfactory performance in improving adhesion and enhancing strength. The crumb rubbers after pretreatment by modifiers are shown in Figure 3.

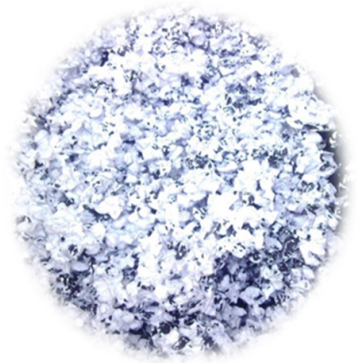

(a)

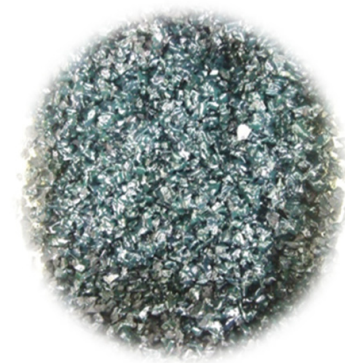

(b)

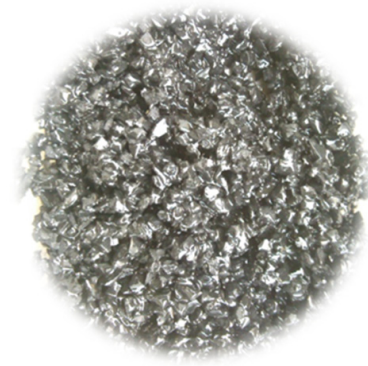

(c)

Figure 3. Cont. 


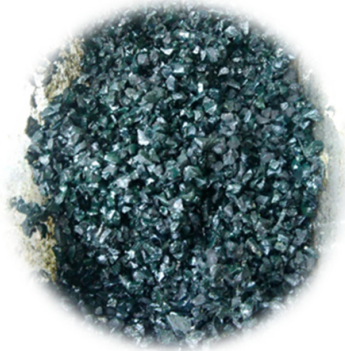

(d)

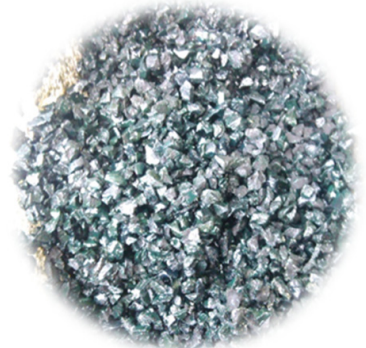

(e)

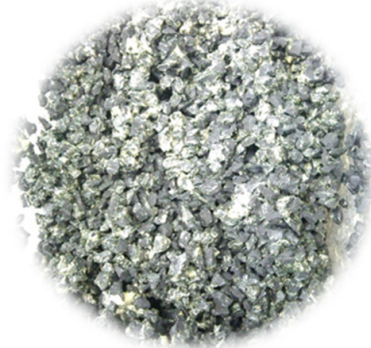

(f)

Figure 3. Crumb rubber after pretreatment. (a) Emulsion; (b) ethoxyline resin; (c) synthetic resin; (d) amino-acrylate; (e) chloroprene adhesive; (f) unsaturated resins.

\subsection{Mixture Proportion}

This study consisted of one plain concrete as the control and 9 crumb rubber concretes. All of the concretes were designed at a constant water-cement ratio of 0.42 . Crumb rubber was used as the replacement for an equal part of fine aggregate and mixture. Considering the different specific gravities of crumb rubber and mineral materials, the replacement with crumb rubber was conducted based on the volume other than weight $[29,30]$. The replacement levels of crumb rubber varied from $5 \%$ to $20 \%$ by volume for fine aggregate and from $1 \%$ to $10 \%$ for the concrete mixture. The final proportions were determined by several trials, as summarized in Table 1 . The slumps of the designed mixture varied between 30 and $60 \mathrm{~mm}$, which ensured the workability of concrete.

Table 1. Mixture proportions of crumb rubber concrete.

\begin{tabular}{|c|c|c|c|c|c|c|}
\hline \multirow{2}{*}{ Mix } & \multirow{2}{*}{$\begin{array}{c}\text { Rubber } \\
\text { Content }(\%)\end{array}$} & \multicolumn{5}{|c|}{ Weight per Cubic Meter $\left(\mathrm{kg} / \mathrm{m}^{3}\right)$} \\
\hline & & Water & Cement & Fine Aggregate & Coarse Aggregate & Crumb Rubber \\
\hline $\mathrm{RC}$ & 0 & 180 & 430 & 593 & 1197 & 0 \\
\hline \multicolumn{7}{|c|}{ Fine aggregate is replaced by crumb rubber } \\
\hline CF1 & 5 & 180 & 430 & 563.4 & 1197 & 13.4 \\
\hline CF2 & 10 & 180 & 430 & 533.7 & 1197 & 26.8 \\
\hline CF3 & 15 & 180 & 430 & 504.1 & 1197 & 40.2 \\
\hline CF4 & 20 & 180 & 430 & 474.4 & 1197 & 56.3 \\
\hline \multicolumn{7}{|c|}{ Mixture is replaced by crumb rubber } \\
\hline CM1 & 1 & 178.2 & 425.7 & 587.1 & 1185.0 & 12 \\
\hline CM2 & 3 & 174.6 & 417.1 & 575.2 & 1161.1 & 36 \\
\hline CM3 & 5 & 171.0 & 408.5 & 563.4 & 1137.2 & 60 \\
\hline CM4 & 10 & 162.0 & 387.0 & 533.7 & 1077.3 & 120 \\
\hline
\end{tabular}

Note: $\mathrm{RC}$ represents the reference concrete; $\mathrm{CF}$ and $\mathrm{CM}$ represent the concretes produced by replacing fine aggregate and mixture with crumb rubber, respectively.

\subsection{Preparation of Specimens}

Concrete specimens were produced as per the JTG E30-2005 standard [31]. Mixing of the mixture was conducted by a power-driven revolving pan mixer. In order to achieve a more homogenous distribution of rubber particles in the mixture with less entrapped air, the pretreatment of crumb rubber was performed for 5 min before being added into the mixer. The mixing procedure was started with 2 min of pre-mixing of cement, aggregates and crumb rubber. Then, an additional 2 min of mixing were conducted after adding the water. After mixing, the mixture was poured into the molds with three layers. A vibration for five seconds was performed after rodding 25 times for each layer. All specimens were removed from the molds after $24 \mathrm{~h}$ and cured in the conditions of $20 \pm 3{ }^{\circ} \mathrm{C}$ and $95 \%$ relative humidity. Prismy specimens $(150 \mathrm{~mm} \times 150 \mathrm{~mm} \times 300 \mathrm{~mm})$ were used to test the 
modulus of elasticity and axial compressive strength. Cube specimens $(150 \mathrm{~mm} \times 150 \mathrm{~mm} \times 150 \mathrm{~mm})$ were produced for measuring compressive strength, splitting tensile strength and durability.

\subsection{Test Methods}

Compressive strength, splitting tensile strength, axial compressive strength and the modulus of elasticity of hardened concrete were measured as per GB/T 50081-2002 [32]. Compressive strength, splitting tensile strength and axial compressive strength were performed on a compression testing machine of a 200-tonne capacity by crushing the specimens cured for 28 days. The modulus of elasticity was tested in the elastic range for concrete specimens at 28 days. Load was applied gradually with a rate of $0.5-0.8 \mathrm{MPa} / \mathrm{s}$, and the limit load was not larger than $1 / 3$ of the axial compressive strength. The applied load and corresponding deformation were measured by a pressure meter and a dial indicator.

Concrete specimens of $150 \mathrm{~mm}$ in size cured for 90 days were used to test the durability (freezing-thawing resistance and sulfate resistance) according to GB/T 50082-2009 [33]. The resistance of concrete against freezing and thawing was assessed by the strength loss rate after twenty-five cycles of freezing and thawing, as calculated by Equation (1).

$$
\Delta f_{c}=\frac{f_{c 0}-f_{c n}}{f_{c 0}} \times 100
$$

where $\Delta f_{c}$ is the strength loss rate of concrete. $f_{c n}$ is the compressive strength of concrete experiencing twenty-five cycles of freezing and thawing. Additionally, $f_{c 0}$ is the compressive strength of the control concrete.

In the case of sulfate resistance, the specimens were immersed in sulfate solution. Then, the waterish specimens were dried at a constant temperature of $80 \pm 5^{\circ} \mathrm{C}$. The anti-corrosion coefficient of concrete after fifteen cycles of drying and soaking was calculated as Equation (2).

$$
K_{f}=\frac{f_{c n}}{f_{c 0}} \times 100
$$

where $K_{f}$ is the anti-corrosion coefficient; $f_{c n}$ is the compressive strength of the tested concrete after fifteen cycles of drying and soaking; $f_{c 0}$ is the compressive strength of the control concrete.

\section{Results and Discussion}

The mechanical properties and durability of concrete were significantly affected by introducing crumb rubber into concrete. In this paper, the variation of properties in concrete with the changing of rubber content was investigated. Additionally, the effect of modifiers was evaluated.

\subsection{Mechanical Properties}

The mechanical properties of crumb rubber concrete were tested and are listed in Table 2. The compressive strength of crumb rubber concrete cured for 28 days was lower than that of the control concrete $(34.76 \mathrm{MPa})$. It was also observed that the compressive strength of $\mathrm{CF}$ (crumb rubber replacing fine aggregate) reduced from $34.76 \mathrm{MPa}$ down to $33.41 \mathrm{MPa}$ with increasing rubber content from $0 \%$ to $20 \%$. The minimum compressive strength at the $20 \%$ replacement level satisfied the strength requirement of $\mathrm{C} 30$ concrete. When $5 \%$ of the total mixture was replaced, the compressive strength had an acceptable value of $25.38 \mathrm{Mpa}$. However, a reduction (44\%) was observed at the $10 \%$ replacement level. Compared to the replacement of mixture, replacing the fine aggregate with crumb rubber led to a marginal decline of the compressive strength.

The splitting tensile strength of crumb rubber concrete cured at 28 days was measured, as shown in Figure 4. It was observed that the splitting tensile strength decreased with the increase in the volume percentage of crumb rubber. Similar to compressive strength, the reduction in the splitting tensile strength of CF is lesser compared to the CM (crumb rubber replacing mixture). This was 
because replacing mixture with crumb rubber reduced the mass of the cement. The splitting tensile strength was weakened due to the loss of binding material. Moreover, the ratio of the reduction in the splitting tensile strength was lower than the compressive strength, which was owed to the rubber providing a better bridge between propagated cracks and limiting their development [34]. When 20\% fine aggregate was replaced by crumb rubber, the splitting tensile strength decreased by $2.5 \%$, whereas compressive strength decreased by $3.9 \%$.

Table 2. Mechanical properties of crumb rubber concrete.

\begin{tabular}{ccccccccccc}
\hline Mixture & RC & \multicolumn{4}{c}{ CF } & \multicolumn{4}{c}{ CM } \\
\hline Rubber content (\%) & 0 & 5 & 10 & 15 & 20 & 1 & 3 & 5 & 10 \\
Compressive strength (MPa) & 34.76 & 34.52 & 34.19 & 33.82 & 33.41 & 31.60 & 29.99 & 25.38 & 19.33 \\
Splitting tensile strength (MPa) & 2.35 & 2.33 & 2.32 & 2.31 & 2.29 & 2.15 & 2.14 & 1.86 & 1.46 \\
Axial compressive strength (MPa) & 23.73 & 23.41 & 22.70 & 22.34 & 21.29 & 22.55 & 21.20 & 19.96 & 15.47 \\
Modulus of elasticity (GPa) & 31.75 & 29.60 & 27.88 & 26.71 & 24.73 & 29.22 & 21.88 & 17.74 & 13.42 \\
\hline
\end{tabular}

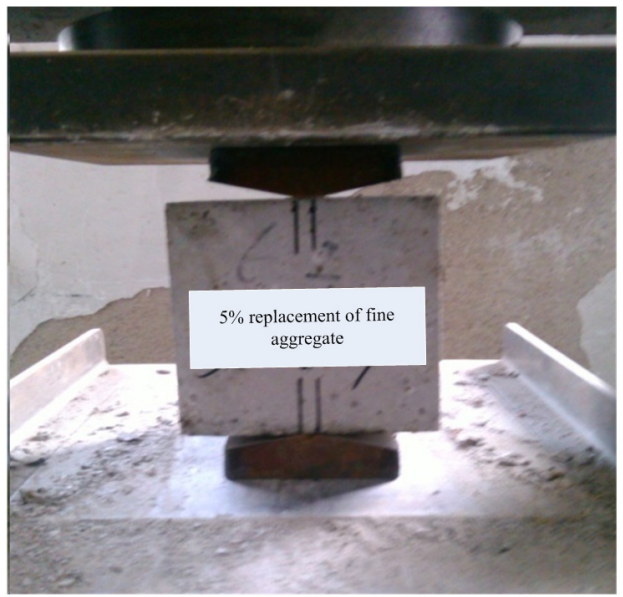

Figure 4. Splitting tensile strength test.

The reduction in axial compressive strength was similar to the compressive strength. It decreased with the increasing of the percentage content of crumb rubber. When the mixture was replaced by crumb rubber, the axial compressive strength significantly decreased as compared to the concrete with fine aggregate replacement. There was a strong correlation between the axial compressive strength and the replacement volume of crumb rubber.

The modulus of elasticity represented the deformation capacity of concrete. The test photograph is shown in Figure 5. It was observed that the modulus of elasticity for rubberized concrete decreased with the increase of the replacement level of crumb rubber. In the case of $C F$, the modulus of elasticity was reduced from $31.75 \mathrm{GPa}$ down to $24.73 \mathrm{GPa}$ with the increasing rubber replacement level from $0 \%$ to $20 \%$. The reduction in the modulus of elasticity was higher when the mixture was replaced. Rubber particles had a low modulus of elasticity with respect to mineral aggregate, which resulted in the weak resistance to external applied load. Due to this, crumb rubber concrete exhibited an obvious deformation performance and better toughness.

There are many reasons accounting for the lower strength of crumb rubber concrete [14]. Firstly, the adhesion of rubber particles and cement paste is weaker than the mineral aggregate. Secondly, the distribution of rubber particles in the concrete mixture is non-homogenous, due to the lower specific gravity compared to other materials. Thirdly, the hydrophobic nature of rubber particles takes bubbles into the concrete mixture and increases the air content. Due to the above reasons, the mechanical strength is reduced when the crumb rubber is introduced into the concrete. 


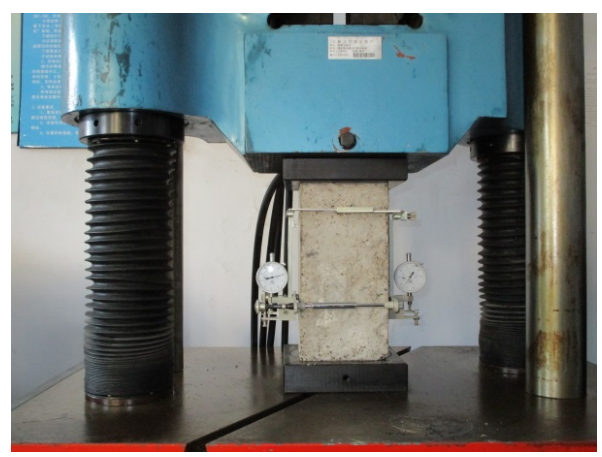

Figure 5. Modulus of elasticity test.

\subsection{Durability}

Freezing-thawing resistance and sulfate resistance are the important aspects of the durability of concrete. In this paper, the freezing-thawing resistance and sulfate resistance of crumb rubber concrete were investigated. Additionally, the effect of crumb rubber content on freezing-thawing resistance and sulfate resistance was analyzed and discussed.

Crumb rubber concrete cured for 90 days was set in the refrigerator for freezing, as shown in Figure 6. Additionally, thawing was performed in water of $18-20^{\circ} \mathrm{C}$. The strength of crumb rubber concrete after twenty-five cycles of freezing-thawing was tested. The strength loss ratio was calculated based on Equation (1) and is listed in Table 3. It can be seen that the concrete including crumb rubber had good resistance against freezing-thawing compared to the reference concrete. The strength loss ratio of the reference concrete was $5.8 \%$, while the concrete with $20 \%$ replacement of fine aggregate was $2.7 \%$, and concrete with $10 \%$ replacement of the total mixture was $2.0 \%$. The influence of mixture replacement was more significant than the fine aggregate replacement. In addition, the increasing of rubber content generally improved the freezing-thawing resistance of concrete. However, when the replacement level exceeded a certain extent ( $5 \%$ total mixture), the improvement of freezing-thawing resistance was not obvious.

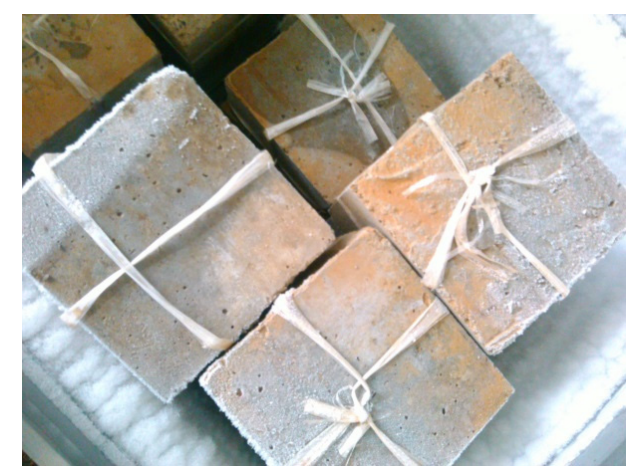

Figure 6. Freezing-thawing of crumb rubber concrete.

Table 3. Durability of crumb rubber concrete.

\begin{tabular}{ccccccccccc}
\hline Mixture & RC & \multicolumn{3}{c}{ CF } & \multicolumn{4}{c}{ CM } \\
\hline Rubber content (\%) & 0 & 5 & 10 & 15 & 20 & 1 & 3 & 5 & 10 \\
Strength loss ratio (\%) & 5.8 & 4.8 & 3.2 & 3.1 & 2.7 & 5.1 & 4.2 & 2.1 & 2.0 \\
Anti-corrosion coefficient (\%) & 96.1 & 96.7 & 97.4 & 97.7 & 98.4 & 96.2 & 96.9 & 97.0 & 97.2 \\
\hline
\end{tabular}

The crumb rubber concrete after sulfate corrosion is illustrated in Figure 7. And the anti-corrosion coefficient of crumb rubber concrete cured at 90 days is shown in Table 3. There was more loss in 
compressive strength for concrete containing less crumb rubber in sulfate corrosion. Furthermore, the anti-corrosion coefficient gradually increased with the increase in the percentage of crumb rubber in concrete. In the case of $\mathrm{CF}$, the maximum anti-corrosion coefficient (98.4\%) was recorded for the concrete with $20 \%$ crumb rubber, whereas the minimum value was $96.1 \%$ for concrete with $0 \%$ crumb rubber. A similar trend could be observed for the concrete with mixture replacement. However, exceeding $5 \%$ replacement of mixture by crumb rubber could not significantly enhance sulfate resistance.

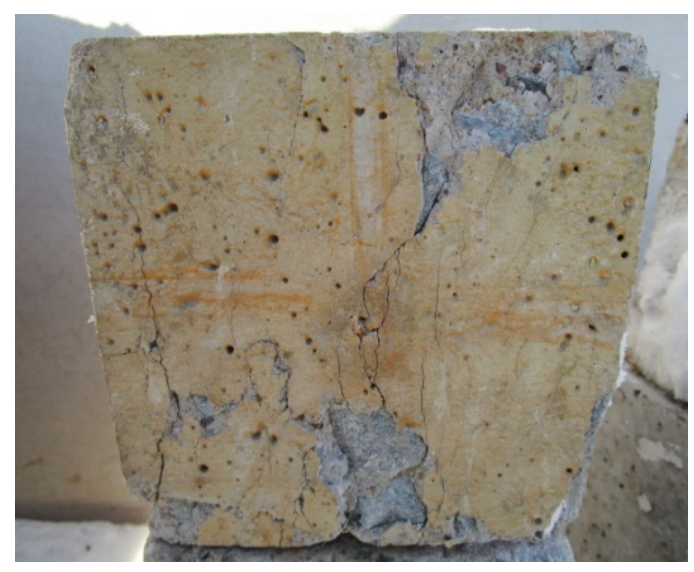

Figure 7. Sulfate corrosion for crumb rubber concrete.

The crumb rubber particles in the rubberized concrete can prevent the formation of cracks and material separation. This may be the reason for the good performance to resisting freezing-thawing and sulfate attack for crumb rubber concrete [3,35].

\subsection{Effect of Modifiers}

As can be seen from the above study about the mechanical properties and durability of crumb rubber concrete, $5 \%$ replacement of the total volume of mixture resulted in a high decrease of strength. From a practical viewpoint, the rubber content should not exceed $5 \%$ of the total volume of the mixture due to the negative effect on strength. Therefore, crumb rubber concrete with $5 \%$ replacement of total mixture was selected to investigate the effect of modifiers on the properties of rubberized concrete.

Modified crumb rubber concrete was produced by introducing crumb rubber after pretreatment using modifiers. Compressive strength, splitting tensile strength and axial compressive strength were tested. Compared to the measured strength of unmodified crumb rubber concrete, the percentage was calculated, and corresponding results are listed in Table 4. Moreover, the effect of six pretreatment methods on the mechanical properties is illustrated in Figure 8. As can be seen from Table 4 and Figure 8 , the effects of modifiers on the mechanical properties were different from each other. The majority had a positive influence on enhancing the strength of crumb rubber concrete. However, the modifier of emulsion reduced the compressive strength and axial compressive strength to $79 \%$ and $90 \%$, respectively. Unsaturated resins decreased the splitting tensile strength to $97 \%$. These two modifiers caused negative effects on the improvement of the mechanical strength of crumb rubber concrete. It had been found that the pretreatment using synthetic resin significantly increased the strength as compared to other modifiers. The compressive strength, splitting tensile strength and axial compressive strength of crumb rubber concrete prepared with pretreated rubber using synthetic resin increased $12 \%, 40 \%$ and $5 \%$, respectively, as compared to the untreated rubber. Therefore, the modifier of synthetic resin could be accepted to increase the mechanical strength of crumb rubber concrete. 
Table 4. Mechanical properties of modified crumb rubber concrete.

\begin{tabular}{cccc}
\hline \multirow{2}{*}{ Modifiers } & \multicolumn{3}{c}{ Mechanical Properties } \\
\cline { 2 - 4 } & $\begin{array}{c}\text { Compressive } \\
\text { Strength MPa (\%) }\end{array}$ & $\begin{array}{c}\text { Splitting Tensile } \\
\text { Strength MPa (\%) }\end{array}$ & $\begin{array}{c}\text { Axial Compressive } \\
\text { Strength MPa (\%) }\end{array}$ \\
\hline None & $25.38(100)$ & $1.86(100)$ & $19.96(100)$ \\
Emulsion & $20.15(79)$ & $2.12(114)$ & $17.93(90)$ \\
Ethoxyline resin & $27.44(108)$ & $2.44(131)$ & $20.03(100)$ \\
Synthetic resin & $28.40(112)$ & $2.61(140)$ & $20.96(105)$ \\
Amino-acrylate & $25.90(102)$ & $2.30(124)$ & $20.80(104)$ \\
Chloroprene adhesive & $26.24(103)$ & $2.26(122)$ & $20.40(102)$ \\
Unsaturated resins & $26.12(103)$ & $1.80(97)$ & $20.07(101)$ \\
\hline
\end{tabular}

Note: the percentage in brackets is the ratio of the measured value of modified crumb rubber concrete and that of the unmodified crumb rubber concrete.

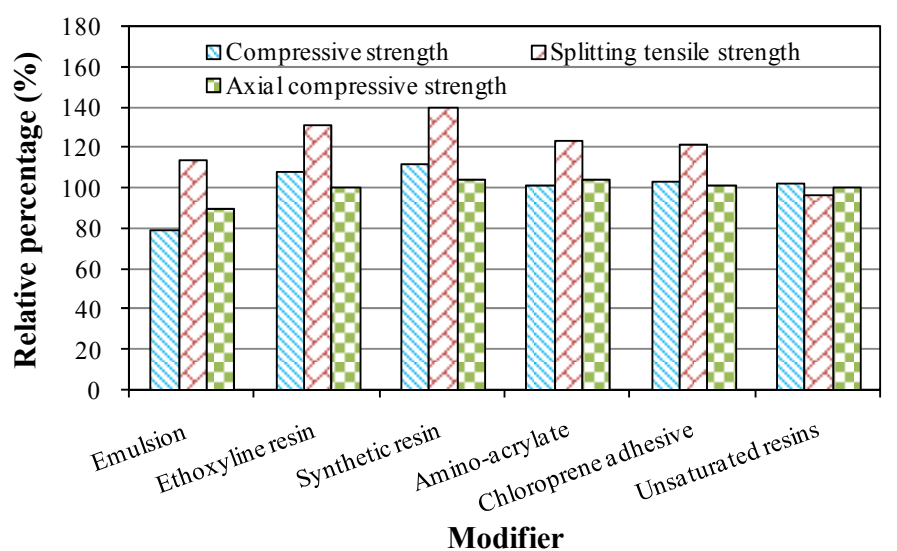

Figure 8. Effect of modifiers on mechanical properties.

The effect of pretreatment methods on freezing-thawing resistance and sulfate resistance was investigated. Additionally, the testing results are listed in Table 5. Figure 9 reports the difference in the durability of crumb rubber concrete modified by six modifiers. It was indicated that the anti-corrosion coefficients of crumb rubber concrete modified by six modifiers were all larger than $97 \%$, which indicated that the pretreatments for the crumb rubber improved the ability of crumb rubber concrete to resist sulfate corrosion. Ethoxyline resin and chloroprene adhesive enhanced the resistance against sulfate corrosion more significantly with anti-corrosion coefficients of $99.0 \%$ and $99.2 \%$, respectively. As for the freezing-thawing resistance, the strength loss ratios of crumb rubber concrete modified by ethoxyline resin and unsaturated resins were larger than $5 \%$, which indicated that the ability of resisting freezing-thawing was not acceptable. Synthetic resin significantly reduced the strength loss ratio to $1.2 \%$, which obviously improved the performance of freezing-thawing resistance. Due to the similar effect of pretreatment methods on sulfate resistance, the optimal modifier was selected based on the improvement of the freezing-thawing resistance. Therefore, synthetic resin was selected as the optimal modifier because of excellent freezing-thawing resistance and acceptable sulfate resistance.

Table 5. Durability of modified crumb rubber concrete.

\begin{tabular}{ccc}
\hline Modifiers & Strength Loss Ratio (\%) & Anti-Corrosion Coefficien (\%) \\
\hline Emulsion & 2.2 & 97.3 \\
Ethoxyline resin & 6.7 & 99.0 \\
Synthetic resin & 1.2 & 97.9 \\
Amino-acrylate & 1.9 & 98.1 \\
Chloroprene adhesive & 3.5 & 99.2 \\
Unsaturated resins & 6.0 & 97.8 \\
\hline
\end{tabular}




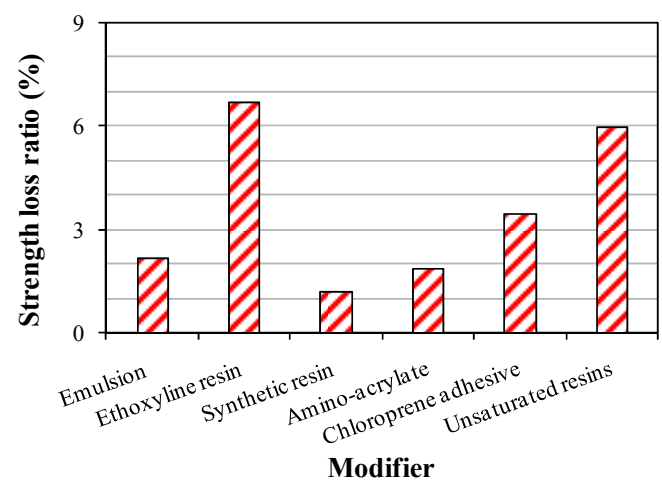

(a)

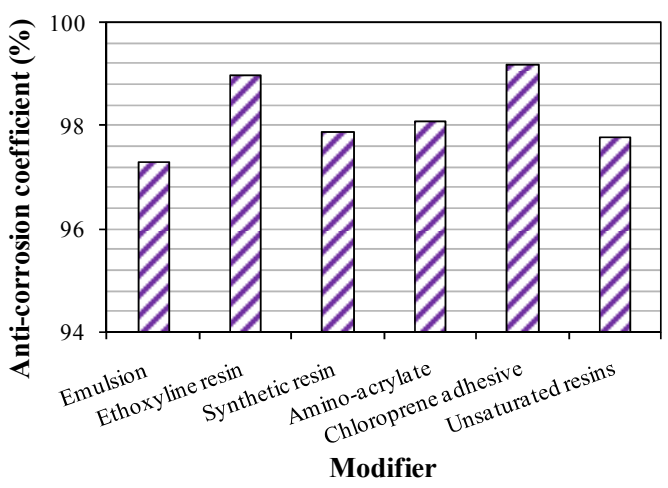

(b)

Figure 9. Durability of modified crumb rubber concrete. (a) Freezing-thawing resistance; (b) sulfate resistance.

Crumb rubber concrete prepared with modified rubber had an obvious improvement in mechanical properties and durability compared to untreated rubber, which could be the result of better bonds between rubber particles and cement paste. Additionally, the treated rubber by modifiers could block the early initiation of internal cracks, which enhanced the freezing-thawing resistance and sulfate resistance [35]. Comprehensive analysis about the effect of six modifiers on the mechanical and durability properties indicated that synthetic resin was the optimal modifier because of its advantages in improving the mechanical and durability properties of crumb rubber concrete.

\section{Conclusions}

In this paper, crumb rubber concretes with different replacement forms and replacement levels were produced. The effect of the volume content of crumb rubber and pretreatment methods on the performances of concrete was investigated. The following conclusions have been obtained.

(1) Adding crumb rubber into concrete resulted in a significant decrease of the mechanical properties, but increased the durability. The effect caused by replacing the mixture with crumb rubber was higher than that caused by fine aggregate replacement.

(2) Compressive strength, splitting tensile strength, axial compressive strength and the modulus of elasticity were reduced with the increasing percentage content of crumb rubber, while freezing-thawing resistance and sulfate resistance were improved. A 20\% replacement of fine aggregate and a 5\% replacement of the total mixture with crumb rubber met the safety strength requirements of concrete and had excellent durability.

(3) The negative effect of crumb rubber on mechanical strength could be minimized and avoided by pretreatment of the crumb rubber using modifiers. These pretreatments enhanced the adherence between the rubber and cement paste and achieved the uniform distribution of rubber particles in mixture.

(4) Synthetic resin significantly improved the mechanical and durability properties of crumb rubber concrete as compared to the other modifiers. The compressive strength, splitting tensile strength and axial compressive strength of crumb rubber concrete prepared with pretreated rubber using synthetic resin increased $12 \%, 40 \%$ and $5 \%$, respectively. Additionally, the strength loss ratio after 25 cycles of freezing-thawing was reduced to $1.2 \%$.

Acknowledgments: The authors express their appreciation for the financial support of the National Natural Science Foundation of China under Grants Nos. 51378236, 51408258 and 51578263; the China Postdoctoral Science Foundation funded projects (Nos. 2014M560237 and 2015T80305); the Fundamental Research Funds for the Central Universities (JCKYQKJC06); and Science \& Technology Development Program of Jilin Province (20140203002SF).

Author Contributions: Hanbing Liu conceived of and designed the experiments. Tao Sha performed the experiments. Xianqiang Wang analyzed the data and wrote the paper. Yubo Jiao edited and audited the content.

Conflicts of Interest: The authors declare no conflict of interest. 


\section{References}

1. Su, H.; Yang, J.; Ling, T.C.; Ghataora, G.S.; Dirar, S. Properties of concrete prepared with waste tyre rubber particles of uniform and varying sizes. J. Clean. Prod. 2015, 91, 288-296. [CrossRef]

2. Pacheco-Torgal, F.; Ding, Y.; Jalali, S. Properties and durability of concrete containing polymeric wastes (tyre rubber and polyethylene terephthalate bottles): An overview. Constr. Build. Mater. 2012, 30, 714-724. [CrossRef]

3. Thomas, B.S.; Gupta, R.C.; Panicker, V.J. Recycling of waste tire rubber as aggregate in concrete: Durability-related performance. J. Clean. Prod. 2016, 112, 504-513. [CrossRef]

4. Hernandez-Olivares, F.; Barluenga, G.; Bollati, M.; Witoszek, B. Static and dynamic behavior of recycled tyre rubber-filled concrete. Cem. Concr. 2002, 32, 1587-1596. [CrossRef]

5. Yung, W.H.; Yung, L.C.; Hua, L.H. A study of the durability properties of waste tire rubber applied to self-compacting concrete. Constr. Build. Mater. 2013, 41, 665-672. [CrossRef]

6. Thomas, B.S.; Gupta, R.C. Properties of high strength concrete containing scrap tire rubber. J. Clean. Prod. 2016, 113, 86-92. [CrossRef]

7. Way, G.; Evans, R. Rubberised Bitumen in Road Construction; The Waste \& Resources Action Programme: Banbury, UK, 2006.

8. Mohammadi, I.; Khabbaz, H. Challenges associated with optimisation of blending, mixing and compaction temperature for asphalt mixture modified with crumb rubber modifier (CRM). Appl. Mech. Mater. 2012, 256-259, 1837-1844. [CrossRef]

9. Flores-Medina, D.; Medina, N.F.; Hernández-Olivares, F. Static mechanical properties of waste rests of recycled rubber and high quality recycled rubber from crumbed tires used as aggregate in dry consistency concretes. Mater. Struct. 2014, 47, 185-1193. [CrossRef]

10. Thomas, B.S.; Gupta, R.C. Long term behavior of cement concrete containing discarded tire rubber. J. Clean. Prod. 2015, 102, 78-87. [CrossRef]

11. Ghaly, A.; Cahill, J. Correlation of strength, rubber content, and water to cement ratio in rubberized concrete. Can. J. Civil Eng. 2005, 32, 1075-1081. [CrossRef]

12. Issa, C.A.; Salem, G. Utilization of recycled crumb rubber as fine aggregates in concrete mix design. Constr. Build. Mater. 2013, 42, 48-52. [CrossRef]

13. Emira, N.; Bajaba, N. The effect of rubber crumbs addition on some mechanical properties of concrete composites. Int. J. Mech. Syst. Eng. 2012, 2, 53-58.

14. Mohammadi, I.; Khabbaz, H.; Vessalas, K. In-depth assessment of Crumb Rubber Concrete (CRC) prepared by water-soaking treatment method for rigid pavements. Constr. Build. Mater. 2014, 71, 456-471. [CrossRef]

15. Corinaldesi, V.; Mazzoli, A.; Moriconi, G. Mechanical behavior and thermal conductivity of mortars containing waste rubber particles. Mater. Des. 2011, 32, 1646-1650. [CrossRef]

16. Nguyen, T.H.; Toumi, A.; Turatsinze, A. Mechanical properties of steel fiber reinforced and rubberized cement-based mortars. Mater. Des. 2010, 31, 641-647. [CrossRef]

17. Holmes, N.; Browne, A.; Montague, C. Acoustic properties of concrete panels with crumb rubber as a fine aggregate replacement. Constr. Build. Mater. 2014, 73, 195-204. [CrossRef]

18. Khaloo, A.R.; Dehestani, M.; Rahmatabadi, P. Mechanical properties of concrete containing a high volume of tire-rubber particles. Waste Manag. 2008, 28, 2472-2482. [CrossRef] [PubMed]

19. Ling, T.C.; Nor, H.M.; Hainin, M.R.; Chik, A.A. Laboratory performance of crumb rubber concrete block pavement. Int. J. Pavement Eng. 2009, 10, 361-374. [CrossRef]

20. Zheng, L.; Huo, X.S.; Yuan, Y. Strength, modulus of elasticity, and brittleness index of rubberized concrete. J. Mater. Civ. Eng. 2008, 20, 692-699. [CrossRef]

21. Sukontasukkul, P.; Tiamlom, K. Expansion under water and drying shrinkage of rubberized concrete mixed with crumb rubber with different size. Constr. Build. Mater. 2012, 29, 520-526. [CrossRef]

22. Batayneh, M.; Marie, I.; Asi, I. Promoting the use of crumb rubber concrete in developing countries. J. Waste Manag. 2008, 28, 2171-2176. [CrossRef]

23. Benazzouk, A.; Douzane, O.; Langlet, T.; Mezreb, K.; Roucoult, J.M.; Quéneudec, M. Physico-mechanical properties and water absorption of cement composite containing shredded rubber wastes. Cem. Concr. Compos. 2007, 29, 732-740. [CrossRef] 
24. Raghavan, D.; Huynh, H.; Ferraris, C. Workability, mechanical properties, and chemical stability of a recycled tyre rubber filled cementitious composite. J. Mater. Sci. 1998, 33, 1745-1752. [CrossRef]

25. Segre, N.; Joekes, I. Use of tire rubber particles as addition to cement paste. Cem. Concr. Res. 2000, 30, 1421-1425. [CrossRef]

26. Oiknomou, N.; Stefanidou, M.; Mavridou, S. Improvement of the bonding between rubber tire particles and cement paste in cement products. In Proceedings of the 15th Conference of the Technical Chamber of Greece, Alexandroupoli, Greece, 25-27 October 2006; pp. 234-242.

27. National Standard of the People's Republic of China. Common Portland Cement (GB175-2007); General Administration of Quality Supervision, Inspection and Quarantine of the People's Republic of China (AQSIQ): Beijing, China, 2008

28. Gesoğlu, M.; Güneyisi, E.; Khoshnaw, G.; İpek, S. Abrasion and freezing-thawing resistance of pervious concretes containing waste rubbers. Constr. Build. Mater. 2014, 73, 19-24. [CrossRef]

29. Khorrami, M.; Vafai, A.; Khalilitabas, A.; Desai, C.S.; Ardakani, M. Experimental investigation on mechanical characteristics and environmental effects on rubber concrete. Int. J. Concr. Struct. Mater. 2010, 4, 17-23. [CrossRef]

30. Siddique, R.; Naik, T.R. Properties of concrete containing scrap-tire rubber-an overview. Waste Manag. 2004, 24, 563-569. [CrossRef] [PubMed]

31. National Standard of the People's Republic of China. Test Methods for Cement and Concrete for Highway Engineering (JTG E30-2005); Ministry of Transport of the People's Republic of China: Beijing, China, 2006.

32. National Standard of the People's Republic of China. Standard for test Method of Mechanical Properties on Ordinary Concrete (GB/T 50081-2002); Ministry of Construction of the People's Republic of China: Beijing, China, 2003.

33. National Standard of the People's Republic of China. Standard for Test Methods of Long-Term Performance and Durability of Ordinary Concrete (GB/T 50082-2009); Ministry of Housing and Urban-Rural Development of the People's Republic of China (MOHURD): Beijing, China, 2010.

34. Gupta, T.; Chaudhary, S.; Sharma, R.K. Assessment of mechanical and durability properties of concrete containing waste rubber tire as fine aggregate. Constr. Build. Mater. 2014, 73, 562-574. [CrossRef]

35. John, T.; Vernon, R. Mixture proportioning considerations for improved freeze-thaw durability of pervious concrete. Plan. Sustain. Cold Reg. Proc. 2013. [CrossRef]

(C) 2016 by the authors; licensee MDPI, Basel, Switzerland. This article is an open access article distributed under the terms and conditions of the Creative Commons by Attribution (CC-BY) license (http://creativecommons.org/licenses/by/4.0/). 